\title{
Detection and viability of Campylobacter species isolates from different species of poultry and humans in Sokoto State, Nigeria
}

\author{
I. O. Nwankwo ${ }^{1}$, O. O. Faleke ${ }^{1}$, M. D. Salihu ${ }^{1}$, A. A. Magaji ${ }^{1}$, U. Musa², J. Garba ${ }^{3}$ and E. B. Ibitoye ${ }^{4,5}$
}

1. Department of Veterinary Public Health and Preventive Medicine, Faculty of Veterinary Medicine, Usmanu Danfodiyo University, Sokoto, Nigeria; 2. Department of Veterinary Pathology, Faculty of Veterinary Medicine, Usmanu Danfodiyo University, Sokoto, Nigeria; 3. Veterinary Council of Nigeria, North Central Zonal Office, Vom, Plateau State Nigeria; 4. Department of Theriogenology and Animal Production, Faculty of Veterinary Medicine, Usmanu Danfodiyo University, Sokoto, Nigeria; 5. Department of Veterinary Preclinical, Faculty of Veterinary Medicine, Universiti Putra, Malaysia.

Corresponding author: I. O. Nwankwo, e-mail: kinginnoma@yahoo.com,

OOF: femmydayor@yahoo.com, MDS: mdsal70@yahoo.com, AAM: magaji1965@yahoo.com, UM: usmanmusagulma@yahoo.com, JG: grbjhn@yahoo.com,EBI: emmavet2001@hotmail.com Received: 01-01-2016, Accepted: 12-04-2016, Published online: 29-04-2016

How to cite this article: Nwankwo IO, Faleke OO, Salihu MD, Magaji AA, Musa U, Garba J, Ibitoye EB. Detection and viability of Campylobacter species isolates from different species of poultry and humans in Sokoto State, Nigeria. Int J One Health 2016;2: 19-23.

\begin{abstract}
Aim: The study was conducted to determine the prevalence and viability of Campylobacter species isolates from different species of poultry and humans in Sokoto State, Nigeria.

Materials and Methods: A cross-sectional study was performed in the live birds markets, humans on admission and at outpatient clinics in the randomly selected hospitals in Sokoto State. Isolation and characterization of Campylobacter species were performed using standard culture isolation techniques and biochemical characterization. A total of 798 (506 cloacal and 292 fecal) swabs from poultry and humans, respectively, were collected and analyzed. The viability of 307 isolates stored in $15 \%$ glycerol and $85 \%$ tryptone broth at $-20^{\circ} \mathrm{C}$ was determined after $7-13$ months.

Results: A total of 312 (39\%) were positive for Campylobacter species which comprises 119 (30\%), 20 (30\%), 3 (14\%), $9(56 \%), 1(50 \%)$, and $160(55 \%)$ in chicken, guinea fowls, pigeons, ducks, turkey, and humans, respectively. The total of $38(24 \%), 63(39 \%)$, and $59(37 \%)$ humans and $29(19 \%), 79(52 \%)$, and $44(29 \%)$ poultry isolates were positive for Campylobacter jejuni, Campylobacter Coli, and Campylobacter Lari, respectively. A total of 261 (85\%) of the stored isolates were still viable on re-isolation with the viability rates of $41(95 \%), 67(85 \%)$, and $17(59 \%)$ at 7, 9, and 13 months of storage, respectively. There was a negative correlation between months of storage and viability rates. However, there was no significant statistical association $(\mathrm{p}>0.05)$ between prevalence rate and species of poultry.

Conclusion: Campylobacter species have been detected with varying degree of prevalence in both poultry and humans and their ability to survive freezing at $-20^{\circ} \mathrm{C}(95 \%)$ for up to 7 months has been revealed in the study. This is not only a concern to food and livestock industries but also a concern to the public health at large, especially, in view of the study area being considered one of the largest livestock producers in Nigeria. Campylobacteriosis is known to be associated with the cost of gastroenteritis management, antimicrobial resistance, food contamination, and complications such as a paralytic condition called Guillain-Barre syndrome.
\end{abstract}

Keywords: Campylobacter species, humans, poultry, Sokoto, Nigeria.

\section{Introduction}

Campylobacter species are microaerophilic, non-fermentative, non-spore forming, Gram-negative, and oxidase-positive organism [1]. They are thought to be non-pathogenic to older birds and warm-blooded mammals as they serve as reservoirs of infection to other animals and humans [2]. They are found on the mucous membrane of the reproductive and gastrointestinal tracts of different species of birds [3]. Turkey is commonly colonized followed by geese $[4,5]$, ducks, ostriches, quails, and wildbirds, especially migratory

Copyright: Nwankwo, et al. This article is an open access article distributed under the terms of the Creative Commons Attribution 4.0 International License (http://creativecommons.org/licenses/ by/4.0/), which permits unrestricted use, distribution, and reproduction in any medium, provided you give appropriate credit to the original author(s) and the source, provide a link to the Creative Commons license, and indicate if changes were made. The Creative Commons Public Domain Dedication waiver (http:// creativecommons.org/ publicdomain/zero/1.0/) applies to the data made available in this article, unless otherwise stated. ones such as cranes [6]. Ingestion of feed contaminated with fecal materials and ecological factors has been implicated in the infection in birds [7]. Infection may induce transient diarrhea, distention, or focal hemorrhage in the jejunum and mortality in day old chick [8]. Campylobacter spp. appear in rod shape on culture but can change to coccoid form which has been described as "viable but non-culturable" (VBNC) under unfavorable growth conditions [9]. This form cannot grow on normal medium, but the report has shown that they can infect animals and humans [9]. Campylobacter species are widely believed to be among the most common causes of acute bacterial enteritis in human worldwide [10]. There has been an increased frequency of isolation in many developed and developing countries $[11,12]$. Most of the infections have been linked to handling and consumption of contaminated water and food, which includes unpasteurized milk, meat, poultry, shellfish, fruits, and vegetable [13-15]. 
Campylobacter species can survive in food at refrigerated temperature for 1-3 weeks, especially if foods are in air tight containers and for 2-4 weeks under moist, reduced oxygen condition at $4^{\circ} \mathrm{C}$ often outlasting the shelf life of the stored product [16]. Clinical features of infection through contaminated foods or drinks are usually similar across the different species with an incubation period of 2-10 days post-infection [17]. Fever, diarrhea, abdominal cramping, acute appendicitis, and inflammation of some parts of the ileum and jejunum with mesenteric adenitis may occur especially in teenagers or adults [18]. The most serious complication of Campylobacter infection is that of a paralytic condition called Guillain-Barre syndrome followed by Reiter's syndrome which includes arthritis, redness of the eye, and urinary tract signs [18]. The absence of biosecurity and sharing of the same environment with birds by humans, especially in the live bird markets, as observed in the study area, can contribute to Campylobacter infections in humans. Study elsewhere has revealed genetic similarity in Campylobacter isolates from pets, human clinical cases, and retail food isolates [19]. The ability of Campylobacter species to survive in more diverse environmental conditions underscores the importance of this type of study. Although Sokoto state is one of the largest livestock producers in Nigeria there is limited data on viability of Campylobacter species isolates from poultry species and humans.

This study was therefore conducted to determine the prevalence and viability of Campylobacter species isolates from different species of poultry and humans in Sokoto State, Nigeria.

\section{Materials and Methods}

\section{Ethical approval}

Ethical approval was obtained from the Research Ethical Committee of the Faculty of Veterinary Medicine, Usmanu Danfodiyo University Sokoto and the Ministry of Health, Usman Farouk Secretariat Sokoto before this study.

\section{Study area}

The study was carried out in Sokoto State, which is geographically located in the extreme northwest of Nigeria. It lies between the latitudes $12^{\circ} \mathrm{N}-58^{\circ} \mathrm{N}$ and longitudes $4.8^{\circ} \mathrm{E}-6.54^{\circ} \mathrm{E}$ with annual average temperature of $28.3^{\circ} \mathrm{C}$. It has 4 agricultural zones and 23 local government areas (LGAs). It shares boundaries with Zamfara State to the East, the Republic of Niger to the North, and Kebbi State to the West. The State had a human population of 3.7 million people with a population density of 97.7 persons $/ \mathrm{km}^{2}$ and ranked second to Borno State in livestock production with estimated population of indigenous chicken at 3.4 million [20,21].

\section{Visits to live bird markets}

Visits were made to live bird market in each of the selected LGAs in the four agricultural zones of state to seek approval and cooperation from the authorities of the market union and estimate the number of birds during the market days. For each of the live bird market, sampling was done once every 2 weeks to avoid repeat sampling as birds for sales are usually transported from one live bird market to another. Two out of every five birds counted were randomly sampled at each visit. In live bird market that has slaughtered slab/processing points, cloacal swabs were collected outside the 2 weeks that samples were routinely collected from the market to avoid sampling same birds twice at both sales and slaughter. Convenient sampling technique was used in fecal sample collection in humans with the use of labeled swab sticks which were given to volunteers indicating their sex and ages.

\section{Sample size determination}

The minimum sample size for this study was determined by the formula $N=Z^{2} p(1-p) / d^{2}[22]$, where $\mathrm{N}=$ Sample size; $\mathrm{Z}=$ The score for a given interval which is 1.96 (S.E) at $95 \%$ confidence interval; $\mathrm{p}=$ known or estimated prevalence; and $\mathrm{d}=(5 \%)$ level of precision. Previous work in the study area obtained Campylobacter prevalence rate of 38.8\% in birds [23] and 20\% estimated in humans. These values were used for birds and humans, respectively. With the known prevalence, the minimum calculated sample size $(\mathrm{N})$ required for the study in birds was $1.96^{2} \times 0.39 \times 0.61 / 0.05^{2}=365$, and for humans was $1.96^{2} \times 0.20 \times 0.80 / 0.05^{2}=245$. However, because of the low sample size and the increasing population of poultry and humans in the state, a total of 506 and 292 cloacal and human fecal swabs were taken, respectively.

\section{Transportation and processing of samples}

The samples were placed in Amies transport media (CMO425, Oxoid), kept cold with the use of ice block [17] and were transported to the Veterinary Public Health Laboratory, Faculty of Veterinary Medicine, Usmanu Danfodiyo University Sokoto for analysis. Screening of samples for Campylobacter species was done using standard culture isolation and biochemical characterization. Samples were plated directly onto selective media; modified charcoal cefoperazone deoxycholate agar (mCCDA) (OxoidCM0739) and incubated at $42^{\circ} \mathrm{C}$ for $48 \mathrm{~h}$ under microaerophilic condition generated by Campygen ${ }^{\circledR}$ (Oxoid, BR0056) in the anaerobic jar [17].

\section{Identification of Campylobacter species}

Identification of colonies was based on characteristic features on mCCDA plates as creamy or white, moist, flat or slightly raised, extending along the streak line, or regular circular discrete colony [24]. A pure colony selected per sample was Gram-stained and different biochemical tests such as oxidase test, catalase test, and hydrogen sulfide $\left(\mathrm{H}_{2} \mathrm{~S}\right)$ production tests were used. These tests are described in the following sections. 
Oxidase test

Oxidase papers were used to touch the isolates. A dark purple along the contact portion of the paper after few seconds of contact indicates a positive reaction. Campylobacter species are oxidase positive.

\section{Catalase test}

A loop full of pure culture was transferred from the agar onto the surface of a clean, dry glass slide. A drop of $3 \%$ hydrogen peroxide was immediately placed onto the colony on the slide. Effervescence indicates a positive reaction. Campylobacter species such as Campylobacter jejuni, Campylobacter coli, Campylobacter lari and C. hyointestinalis are catalase positive while $C$. upsailensis is catalase negative.

\section{Hydrogen sulfide $\left(\mathrm{H}_{2} \mathrm{~S}\right)$ production test}

Hydrogen sulfide $\left(\mathrm{H}_{2} \mathrm{~S}\right)$ production test, characteristic colony from the selective medium, was touched with a straight inoculating wire. A tube of triple sugar iron (TSI) agar (LAB 53, Lab M. Limited) was inoculated by stabbing the middle of the agar to within $5 \mathrm{~mm}$ from the bottom of the tube and incubated at $37^{\circ} \mathrm{C}$ for $48 \mathrm{~h}$ with a loose cap on the TSI agar. Blackening of the medium indicates hydrogen sulfide production. C. jejuni and C. lari do not produce $\mathrm{H}_{2} \mathrm{~S}$ while $C$. coli produces $\mathrm{H}_{2} \mathrm{~S}$. C. jejuni among the confirmed isolates was identified using the Hippurate hydrolysis test. A pure culture of the isolate was inoculated in $0.4 \mathrm{ml}$ of $1 \%$ sodium hippurate substrate (1 g of sodium hippurate (Sigma) and $99 \mathrm{ml}$ of distilled water) in a tube. The tube was then incubated for $2 \mathrm{~h}$ at $37^{\circ} \mathrm{C}$ and $0.2 \mathrm{ml}$ of $2 \%$ ninhydrin solution (Sigma) were added and further incubated at $37^{\circ} \mathrm{C}$ for an additional $15 \mathrm{~min}$. Color change from pale purple to deep purple or violet indicates hippurate hydrolysis. Sensitivity to cephalothin, nalidixic acid, and metronidazole was done using agar disc diffusion method on mCCDA to further differentiate among species [25]. Three to four loopful of the isolates in the culture were transferred into the storage medium $(15 \%$ glycerol and $85 \%$ tryptone broth) and kept at $-20^{\circ} \mathrm{C}$ for a period of 7-13 months before re-isolation.

\section{Statistical analysis}

The results obtained were presented in tables and percentages. Chi-square test was used to determine any significant statistical association between Campylobacter infection and species of poultry while descriptive statistics was used to analyze the viability rates.

\section{Results}

Out of the 798 samples, a total of 312 (39\%) were positive for Campylobacter. Among the different species of birds, 119 (30\%), 20 (30\%), 3 (14\%), $9(56 \%)$, and $1(50 \%)$ were positive for chicken, guinea fowls, pigeons, ducks, and turkey, respectively while 160 (55\%) were positive for humans (Table-1). In humans, 38 (24\%), 63 (39\%), and 59 (37\%) were C. jejuni, C. coli, and C. lari, respectively. In chicken, the prevalence rates of $23(19 \%), 62(50 \%)$, and $34(29 \%)$ were revealed for $C$. jejuni, C. coli, and C. lari, respectively. C.coli also had higher prevalence rate of $10(50 \%)$ and $7(78 \%)$ in guinea fowl and ducks, respectively, than other species such as $C$. lari which has $7(35 \%)$ and $2(22.2 \%)$ in the same species, respectively while $C$. jejuni had the prevalence rates of $3(15 \%)$ and $1(50 \%)$ in guinea fowl and turkey, respectively. In pigeon, $2(67 \%)$ were $C$. jejuni and $1(33 \%)$ was $C$. lari while $C$. coli was neither isolated from pigeon nor turkey (Table-1). There was no significant statistical association $(\mathrm{p}>0.05)$ between infection rate and species of poultry. The total of $261(85 \%)$ out of 307 isolates were still viable on re-isolation with the viability rates of $41(95 \%), 67(85 \%)$, and $17(59 \%)$ after 7,8 , and 13 months of storage, respectively (Table-2).

\section{Discussion}

Campylobacter infection rates as found in this study revealed that duck, which is a waterfowl and turkey are the most colonized among the different species of poultry. Although duck and turkey showed to have a high prevalence, the sample size was small in this study. Another study has also revealed high prevalence rate in turkey [4]. The high prevalence rate as observed in duck can be attributed to their high affinity to water as some tip-up on the surface of shallow water for forage while others submerge completely and swim under the water in search of food. They can get infected especially when the ground water is contaminated with Campylobacter species [26]. The low infection rate found in chicken could be linked to a common management system operational in Sokoto and most parts of Nigeria. Free-range management system predominates in the study area, and this does

Table-1: Prevalence of Campylobacter species in different species of poultry and humans in Sokoto State.

\begin{tabular}{lccccc}
\hline Sample source & Total sampled & Total (\%) & C. jejuni (\%) & C. coli (\%) & C. lari (\%) \\
\hline Humans & 292 & $160(55)$ & $38(24)$ & $63(39)$ & $59(37)$ \\
Chicken & 400 & $119(30)$ & $23(19.3)$ & $62(50.4)$ & $34(28.6)$ \\
G/fowl & 67 & $20(30)$ & $3(15)$ & $10(50)$ & $7(35)$ \\
Pigeon & 21 & $3(14)$ & $2(66.6)$ & 0 & $1(33.3)$ \\
Duck & 16 & $9(56)$ & $1(100)$ & $7(77.8)$ & $2(22.2)$ \\
Turkey & 2 & $1(50)$ & $67(21)$ & $142(46)$ & 0 \\
Total & 798 & $312(39)$ & $103(33)$ \\
\hline
\end{tabular}

G/fowl=Guinea fowl, C. jejuni=Campylobacter jejuni, C. coli: Campylobacter coli, C. lari=Campylobacter lari 
Table-2: Recovery rate of Campylobacter isolates within 7-13 months of storage at $-20^{\circ} \mathrm{C}$.

\begin{tabular}{lccccc}
\hline $\begin{array}{l}\text { Duration of } \\
\text { storage (months) }\end{array}$ & $\begin{array}{c}\text { Number of poultry } \\
\text { isolates stored }\end{array}$ & $\begin{array}{c}\text { Viable poultry } \\
\text { isolates (\%) }\end{array}$ & $\begin{array}{c}\text { Number of human } \\
\text { isolates stored }\end{array}$ & $\begin{array}{c}\text { Viable human } \\
\text { isolates (\%) }\end{array}$ & $\begin{array}{c}\text { Total viable } \\
\text { isolates (\%) }\end{array}$ \\
\hline 13 & 29 & $17(59)$ & 0 & 0 & $17(59)$ \\
12 & 21 & $20(95)$ & 34 & $28(82)$ & $48(87)$ \\
11 & 0 & 0 & 21 & $19(90)$ & $19(90)$ \\
9 & 30 & $22(73)$ & 48 & $45(94)$ & $67(85)$ \\
8 & 22 & $15(68)$ & 59 & $54(92)$ & $69(85)$ \\
7 & 43 & $41(95)$ & 0 & 0 & $41(95)$ \\
Total & 145 & 115 & 162 & 146 & 261 \\
\hline
\end{tabular}

not encourage coprophagy in the chicken population as opposed to the practice among birds kept in deep litter system. This is supported by the findings that recorded the prevalence rate of $78.4 \%$ in intensively reared poultry and $18.3 \%$ in small-scale rural poultry farming [27]. However, the lower prevalence rate can be due to the population size as other studies have revealed higher prevalence in free-range poultry. The prevalence rates in turkey, pigeon and guinea fowl have revealed the possibilities of infection through feeds since these categories of poultry usually feeds on insects, fruits, seeds, and flowers, and these have been suggested as potential routes of infection in poultry [28]. However, the small sample size used for pigeon and turkey might have contributed to the low prevalence rates. There is wide interaction among these species of birds and human surroundings in the study area where birds are caged together in the same cage and even transported from one live bird markets to another until they are sold. This practice will enhance the possibilities of infection spread and transmission to humans [7].

The prevalence rate of $C$. coli was higher than that of $C$. jejuni and C. lari in both poultry and humans. This was in disagreement with the usual higher isolation rate of C. jejuni than other species [23]. However, it has remained the most isolated species in swine as a major cause of swine dysentery [29]. Both C. coli and $C$. jejuni have been revealed as the most common bacteriological cause of gastroenteritis in humans [30]. On the other hand, C. lari, which is mostly found in wild birds, usually have low prevalence in humans and poultry, but the high detection rates in this study suggest the possibility of transmission from wild birds [31].

The $85 \%$ viability rate of Campylobacter isolates after 7 months of storage was in agreement with the work that revealed all isolates viable after the same period [32]. Frozen poultry can serve as a reservoir of Campylobacter as well as fresh meat. However, freezing meat has been proven to reduce contamination. Furthermore, the ability of Campylobacter to change from viable rod form to VBNC coccoid form that fails to grow on subculture can lead to false negative result on testing for food contamination [9]. Therefore, strict sanitary measures in handling and processing both fresh meat and frozen poultry should be encouraged. This would reduce food contamination and further reduce the spread of Campylobacter infection and development of resistant strains [33].

\section{Authors' Contributions}

The manuscript was drafted by ION. MDS and JG contributed substantially to the conception and design of the study. OOF, AAM, and UM supervised the study and approved the experimental protocol. ION and EBI performed the data and statistical analysis. The manuscript was critically reviewed by ION, JG, OOF, and EBI. All authors read and approved the final manuscript.

\section{Acknowledgments}

The research was funded by ION being part of his Ph.D. thesis. The corporation of the chairpersons and members of live bird sellers associations in Sokoto and the assistance of Chief Medical Officers and other health workers of the hospitals used for sample collection were highly appreciated by the authors. We also thank the Laboratory staff of Veterinary Public Health and Preventive Medicine, Faculty of Veterinary Medicine, Usmanu Danfodiyo University Sokoto, Nigeria, for their assistance throughout the course of the study.

\section{Competing Interests}

The authors declare that they have no competing interests.

\section{References}

1. Snelling WJ, Matsuda M, Moore JE, Dooley JS. Campylobacter jejuni. Lett Appl Microbiol 2005;41:297-302.

2. Sahin O, Kassem II, Shen Z, Lin J, Rajashekara G, Zhang Q. Campylobacter in poultry: Ecology and potential interventions. Avian Dis 2015;59:185-200.

3. Stephens CP, On SL, Gibson JA. An outbreak of infectious hepatitis in commercially reared ostriches associated with Campylobacter coli and Campylobacter jejuni. Vet Microbiol 1998;61:183-90.

4. Cox NA, Stern NJ, Craven SE, Berrang ME, Musgrove MT. Prevalence of Campylobacter and Salmonella in the cecal droppings of turkeys during production. J Appl Poult Res 2000;9:542-3.

5. Aydin F, Atabay HI, Akan M. The isolation and characterization of Campylobacter jejuni subsp. jejuni from domestic geese (Anseranser). J Appl Microbiol 2001;90:637-42.

6. Broman T, Waldenstrom J, Dahlgren D, Carlsson I, Eliasson I, Olsen B. Diversities and similarities in PFGE profiles of Campylobacter jejuni isolated from migrating birds and humans. J Appl Microbiol 2004;96:834-43. 
7. Waldenström J, Broman T, Carlsson I, Hasselquist D, Achterberg RP, Wagenaar JA, et al. Prevalence of Campylobacter jejuni, Campylobacter lari, and Campylobacter coli in different ecological guilds and taxa of migrating birds. Appl Environ Microbiol 2002;68:5911-7.

8. Welkos SL. Experimental gastroenteritis in newly-hatched chicks infected with Campylobacter jejuni. J Med Microbiol 1984;18:233-48.

9. Ikeda N, Karlyshev AV. Putative mechanisms and biological role of coccoid form formation in Campylobacter jejuni. Eur J MicrobiolImmunol (Bp) 2012;2:41-9.

10. Epps SV, Harvey RB, Hume ME, Phillips TD, Anderson RC, Nisbet DJ. Foodborne Campylobacter: Infections, metabolism, pathogenesis and reservoirs. Int J Environ Res Public Health 2013;10:6292-304.

11. Taylor DN. Campylobacter infection in developing countries. In: Nachamkin I, Blaser MJ, editors. Campylobacter jejuni: Current Status and Future Trends. Washington: American Society for Microbiology; 1992. p. 20-30.

12. World Health Organization: Water Sanitation and Health (WSH); Water-related Diseases; 2014. Available from: http://www.who.int/water_sanitation_health/diseases/campylobacteriosis/en. [Last accessed on 2014 Aug 08].

13. deCarvalho AF, da Silva DM, Azevedo SS, Piatti RM, Genovez ME, Scarcelli E. Detection of CDT toxin genes in Campylobacter spp. strains isolated from broiler carcasses and vegetables in São Paulo, Brazil. Braz J Microbiol 2014;44:693-9.

14. Salihu MD, Junaidu AU, Magaji AA, Rabiu ZM. Study of Campylobacter in raw cow milk in Sokoto State, Nigeria. Br J Dairy Sci 2010;1:1-5.

15. O'Mahony E, Buckley JF, Bolton D, Whyte P, Fanning S. Molecular epidemiology of Campylobacter isolates from poultry production units in southern Ireland. PLoS One 2011;6:e28490.

16. Hunt JM, Abeyta C, Tran T. Campylobacter. In: FDAs Bacteriological Analytical Manual Online. $8^{\text {th }}$ ed. RevisionA. 2001. p. 7. Available from: http://www.cfsan.fda.gov/ ebam/bam-7.html. [Last accessed on 2014 May13].

17. Butzler JP. Campylobacter, from obscurity to celebrity. Clin Microbiol Infect 2004;10:868-76.

18. Backert S, Boehm M, Wessler S, Tegtmeyer N. Transmigration route of Campylobacter jejuni across polarized intestinal epithelial cells: Paracellular, transcellular or both? Cell Commun Signal 2013;11:72.

19. Acke E, Carroll C, O’Leary A, McGill K, Kelly L, Lawlor A, et al. Genotypic characterization and cluster analysis of Campylobacter jejuni isolates from domestic pets, human clinical cases and retail food. Ir Vet J 2011;64:6.
20. NPC. Sokoto State Censors Statistical Tables. Abuja: NPC; 2006.

21. Resources Inventory and Management Limited (RIM). Nigerian Livestock Resources. State Reports. Vol. 3. Jardine House, Wesley Street Jersey UK: Resources Inventory and Management Limited; 1992. p. 9-1.

22. Thrusfield M. Estimation of disease prevalence. Veterinary Epidemiology. $2^{\text {nd }}$ ed. Oxford: Blackwell Science;1999. p. 182-5.

23. Salihu MD, Junaidu AU, Oboegbulam SI, Egwu GO, Magaji AA, Abubakar MB, et al. Prevalence of Campylobacter spp. In Nigeria indigenous chicken in Sokoto State Northwestern Nigeria. IJVM2009;7:1.

24. Atabay HI, Corry JE. The isolation and prevalence of Campylobacters from dairy cattle using a variety of methods. J Appl Microbiol 1998;84:733-40.

25. Quinn PJ, Carter ME, Markey B, Carter GR. Campylobacter species. In: Clinical Veterinary Microbiology. London: Wolfe Publishing, an Imprint of Mosby-Year Book Europe Limited; 1994. p. 268-4

26. Ugboma AN, Salihu MD, Magaji AA, Abubakar MB. Prevalence of Campylobacter species in ground water in Sokoto, Sokoto State, Nigeria. Vet World 2013;6:285-7.

27. Robino P, Tomassone L, Tramuta C, Rodo M, Giammarino M, Vaschetti G, et al. Prevalence of Campylobacter jejuni, Campylobacter coli and enteric Helicobacter in domestic and free living birds in North-Western Italy. Schweiz Arch Tierheilkd 2010;152:425-31.

28. Shane SM. The significance of Campylobacter jejuni infection in poultry: A review. Avian Pathol 1992;21:189-213.

29. Gwimi PB, Faleke OO, Salihu MD, Magaji AA, Abubakar MB, Nwankwo IO, et al. Prevalence of Campylobacter species in fecal samples of pigs and humans from Zuru Kebbi State, Nigeria. Int J One Health2015;1:1-5.

30. Centers for Disease Control and Prevention: Campylobacter General Information; 2014. Available from: http://www. cdc.gov/nczved/divisions/dfbmd/diseases/campylobacter. [Last accessed on 2014 Aug12].

31. Mohan V. Faeco-prevalence of Campylobacter jejuni in urban wild birds and pets in New Zealand. BMC Res Notes 2015;8:1

32. Gorman R, Adley CC. An evaluation of five preservation techniques and conventional freezing temperatures of $-20^{\circ} \mathrm{C}$ and $-85^{\circ} \mathrm{C}$ for long-term preservation of Campylobacter jejuni. Lett Appl Microbiol 2004;38:306-10.

33. Gblossi Bernadette G, Eric Essoh A, Elise Solange KN, Natalie G, Souleymane B, LamineSébastien N, et al. Prevalence and antimicrobial resistance of Thermophilic Campylobacter isolated from chicken in Côte D'Ivoire. Int J Microbiol 2012;2012:150612. 